\title{
Evaporated Responsibility: The Collapse of the West Gate Bridge in Melbourne on 15 October 1970
}

\subsection{Characteristics of the Case}

On 15 October 1970, at 11:50AM, part of the West Gate Bridge in Melbourne, span 10-11 of 367 feet length, disintegrated and triggered the collapse of the bridge. Thirty-five men were killed in the disaster. The bridge was still under construction, all those killed were workers or engineers employed on the construction site. What aggravated the catastrophe was that fuel tanks caught fire upon the impact of the debris so that workers died or were severely injured through the flames spreading across the construction compound. A Royal Commission was tasked with the investigation into the origins of the collapse. ${ }^{1}$ It stated that "the disaster is probably the most tragic industrial accident in the history of [the state of] Victoria". ${ }^{2}$

What makes the collapse of the West Gate Bride an "index case"-i.e., a case that exemplifies crucial characteristics of a basically unlikely disaster

${ }^{1}$ Report of Royal Commission into the failure of West Gate Bridge presented to both houses of parliament pursuant to section 7 of the West Gate Bridge Royal Commission act 1970 No.7989 (1971), henceforth quoted as Royal Commission, page number. For a compact overview see also Donald. E. Charrett: West Gate Bridge Melbourne (1970). Australian Construction Law Newsletter \#120 (2008), 28-35.

${ }^{2}$ Royal Commission, 9.

I thank Paul 't Hart very much for pointing me to this Australian tragedy.

(C) The Author(s) 2022

W. Seibel, Collapsing Structures and Public Mismanagement, https://doi.org/10.1007/978-3-030-67818-0_2 
triggered though by typical structural weaknesses and causal mechanisms $^{3}$ - was that it happened in an institutional and professional environment with high safety standards and high levels of auditing, control and transparency. Yet, the disaster resulted from mismanagement that was all but coincidental. The Royal Commission itself stated that "proper and careful regard to the process of structural engineering" were not in place, ${ }^{4}$ a fact that had been left uncorrected by the quasi-public authority in charge, the Lower Yarra Crossing Authority. The main characteristics of the structural engineering of the West Gate Bridge were "unusual"5 indeed. Which, however, only implied that "proper and careful regard" was imperative. Neither the overall design of the bridge nor the process of structural engineering itself caused the disaster but, rather, a lack of coherent control and diligent management.

\subsection{Facts of the Matter}

\subsubsection{Pre-bistory of the Bridge}

The West Gate Bridge was one of the main infrastructure projects of the city of Melbourne and the government of Victoria after World War II. Its purpose was to cross the Lower Yarra River between Port Melbourne and Williamstown. Both Port Melbourne and Williamstown are suburbs located on peninsulas but separated by the Yarra River. A crossing of the Yarra between the two suburbs was traditionally handled by ferries, a means of transportation that was considered increasingly insufficient in the 1950s so that the quest for a more convenient crossing of the Yarra river with substantially amplified capacity — either a tunnel or a bridgebecame a pressing issue of urban development of the entire agglomeration and the state of Victoria (Illustration 2.1).

While the desirability of a high capacity crossing of the Yarra River was undisputed between the government of Victoria, the affected municipalities and local businesses, the Minister for Public Works of the government of Victoria made it clear in discussions held in 1958 that no public funds could be mobilized for this purpose and suggested private funding as an

${ }^{3}$ John Gerring: Case Study Research. Principles and Practices. 2nd ed., Cambridge: Cambridge University Press 2017, 72-74.

${ }^{4}$ Royal Commission, 9.

${ }^{5}$ Ibid. 


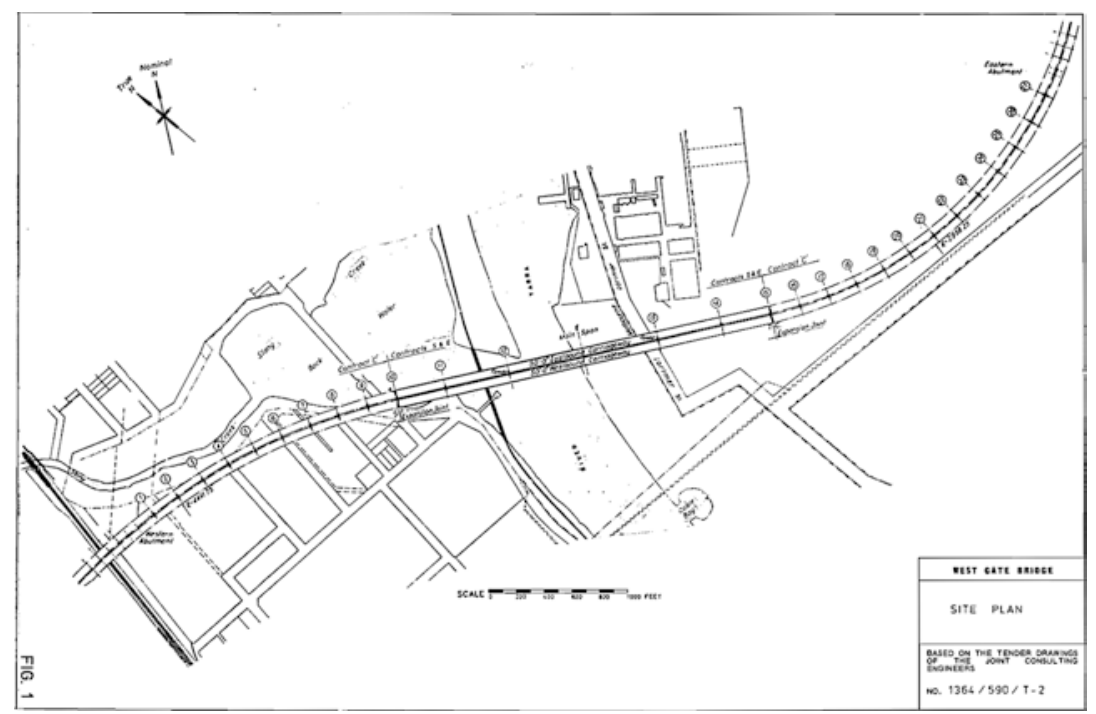

Illustration 2.1 West Gate Bridge, Melbourne, as planned and partly erected before the collapse of 15 October 1970. (Source: Royal Commission, Appendix, p. 123)

alternative. From this emerged a public-private partnership in the form of cooperation between a newly created private company, the Lower Yarra Crossing Company Ltd., and the government of Victoria's Country Roads Board (CRB). The CRB, meanwhile in 1962, also started subsurface investigations into the geological conditions on the banks to the west and the east of the Lower Yarra River. ${ }^{6}$ In 1964, the government of Victoria eventually decided that the crossing of the Lower Yarra River should be performed by way of a high-level bridge that would keep the river open for large scale shipping rather than by way of a tunnel.

The already existing public-private partnership was further developed and formalized in 1965 when the Lower Yarra Crossing Company was purposefully liquidated and replaced by a new company under the name Lower Yarra Crossing Authority Limited which with the approval by the attorney general of Victoria was later given the license to discard the word "Limited" so that the name eventually became "The Lower Yarra Crossing

${ }^{6} \mathrm{Cf}$. for the early history of the West Gate Bridge project Royal Commission, 10-11. 
Authority" (LYCA), or simply—also in the report of the Royal Commission into the failure of the West Gate Bridge- "the Authority". ${ }^{7}$ By the Lower Yarra Crossing Authority Act of 1965, the Authority became a true hybrid institution since, on the one hand, it remained a company entirely comprised of representatives of private enterprises but on the other hand it was given regulatory powers. The general scheme of the relevant legislation was that LYCA was enabled to borrow money on debentures in order to finance the construction of the bridge. The government of Victoria, in 1966, became the guarantor of the repayment of the debenture funds. So, in reality, LYCA became what in British language is known as a QUANGO (quasi-nongovernmental organization). ${ }^{8}$

While the hybrid nature of LYCA already diluted governmental responsibility, the governance structure was especially fragmented on the private business side as well. Which implied predictable fault lines that weakened the effectiveness and accountability of the project management. Representatives of what later became the Lower Yarra Crossing Authority had contacted a British consulting and civil engineering firm with a branch in Melbourne, Maunsell and Partners, in 1964. Since Maunsell had "limited experience with major bridges of structural steel" they contacted, in February 1966, yet another British consultancy and civil engineering firm of, at the time, world-wide reputation, Freeman, Fox and Partners (FF \& P), with the intent of future cooperation. On 7 July 1967, LYCA signed an agreement with Maunsell and FF \& P, now acting as joint consulting engineers. The agreement required Maunsell and FF \& P to develop a detailed plan for the future bridge.

Based on qualification requirements defined in the course of consultations between Maunsell and FF \& P a public tender was called with a closing date of 14 February 1968. The subject of the public tender was divided into three sections according to the main parts of the relevant works and laid down in related contracts whose designation referred to the nature of the works concerned: Contract F for Bridge Foundations, Contract $\mathrm{C}$ for Concrete Bridge Works and Contract S for Steel Bridge Works. Just as the

\footnotetext{
${ }^{7}$ Royal Commission, 11. The abbreviation LYCA used in this chapter is not an official acronym.

${ }^{8}$ The Report of the Royal Commission into the failure of the West Gate Bridge, while being precise and nuanced in its description of the pre-history of the construction of the bridge and the relevant governance structure, refrained from characterizing, let alone criticizing, the hybrid status of the Lower Yarra Crossing Authority.

${ }^{9}$ Royal Commission, 11.
} 
details of the tender documents, the evaluation of the submitted tenders was done in substance by Maunsell and FF \& P. LYCA followed their advice to award Contract $S$ to World Services and Constructions Proprietary Ltd. (WSC), an Australian subsidiary of, according to the Report of the Royal Commission, "a company of international reputation having its base in the Netherlands".${ }^{10}$ Contracts $\mathrm{C}$ and $\mathrm{F}$ were awarded, again according to the advice given by Maunsell and FF \& $\mathrm{P}$, to John Holland (Constructions) Proprietary Ltd. (JHC), a Melbourne-based company specialized in concrete work. The three contracts were signed in July 1968.

\subsubsection{Delayed Construction and Risk-Increasing Contractual Re-arrangements}

By the very nature of the construction and the related time sequence, Contracts F (Bridge Foundations) and C (Concrete Bridge Works) were the first to be executed which happened by a single contractor, Melbournebased JHC. These works had started even before the formal signing of both contracts as early as April 1968 and work under Contract F was completed on 25 September 1969 while work under Contract C according to the Report of the Royal Commission "also proceeded satisfactorily" and was supposed to be completed in March 1971. ${ }^{11}$

It was evident and certainly anticipated that the steelworks were the more complex, demanding and necessarily time consuming portion of the entire construction works. Nonetheless, practical completion of those works was envisaged for the end of the year 1970. They were assigned to World Services and Constructions Proprietary Ltd. (WSC), a Dutch firm represented in Australia by a subsidiary. Already at the end of 1969, the Royal Commission stated, "it was perfectly clear that WSC was behind in its programme". ${ }^{12}$ The main reason for the delay of the works to be performed by WSC was that, "this company had a great deal of trouble with labour, and there were many times when all work was stopped owing to strikes". ${ }^{13}$ The strikes were not that much stimulated by insufficient pay or work conditions but by quarrels between individual unions known,

\footnotetext{
${ }^{10}$ Royal Commission, 12 .

${ }^{11}$ Ibid.

${ }^{12}$ Ibid.

${ }^{13}$ Ibid.
} 
according to the Royal Commission, as "Demarcation Disputes". ${ }^{14}$ As a consequence of the strikes and the delay of the completion of the steelworks, WSC came under pressure by its contract counterpart, LYCA. This took the shape of a formal initiative by LYCA requiring WSC to declare why a particular penalty clause of the contract applicable due to the delay of the steelworks should not be enforced. This conflict resulted in a settlement, reached on 16 March 1970, that decisively shaped the rest of the trajectory of decisions and omissions leading to the disaster of 15 October 1970.

According to the settlement between LYCA and WSC of 16 March 1970, WSC was to continue to fabricate the steel boxes that formed the core-components of the girders of the bridge span. The completed boxes would then be handed over to JHC which, according to the new agreement, "would be responsible for all further operations involved in erecting the boxes and completing the construction of the steel portion of the bridge, including all concrete work and black top for the roadway". ${ }^{15}$ Although a formal agreement finalizing the settlement of 16 March 1970 was signed only on 10 July 1970, WSC and JHC started to proceed on the agreed-upon basis as early as the second half of March $1970 .{ }^{16}$

The consequences of the settlement between LYCA and WSC and the resulting division of labor concerning the steelworks between WSC and JHC were heavily detrimental for the entire project management. What is more, the consequences could have been anticipated due to the very nature of the structural engineering concerning the steelworks and the difference in expertise and experience between WSC and JHC. At any rate, splitting up competences and control concerning what was clearly the most ambitious and demanding portion of the entire construction works could and should have been recognized as a grave mistake in the first place.

As a matter of fact, the method of erecting the bridge was both unique and particularly challenging. The structural design was based on box girders with a main span of 2782 feet total length. The steel boxes had to be assembled and connected to each other. Two techniques were available for putting up this core-structure. The conventional way was to assemble the boxes up in the air and having the segments of bridge cantilevered step by step. While this was termed by the Royal Commission the

\footnotetext{
${ }^{14}$ Ibid.

${ }^{15}$ Ibid.

${ }^{16}$ Ibid.
} 
"straightforward method" it would have required temporary support structures many of which inevitably to be founded in the water of the Yarra river and, consequently, neither easily nor expeditiously to erect. Accordingly, it was a plausible and, from a professional vantage point, entirely justifiable alternative to have the individual boxes of the girder structure assembled on the ground and to have them subsequently lifted and put into position at the top of the piers. ${ }^{17}$ At the same time, however, to assemble a span of several boxes on the ground and jack it up into place up in the air meant that, according to the report of the Royal Commission, "the total weight to be lifted would be some 1200 tons to a height of 170 feet". ${ }^{18}$ In the attempt to take advantage of connecting the boxes of the entire span on the ground while reducing the total weight to be lifted, engineers of the initially engaged contractor, WSC, had chosen to assemble each span in two halves on the ground separately, split along the longitudinal axis of the deck of the bridge.

While it was evident that, as always, accuracy and precision was of pivotal importance for every segment of this necessarily complex process of assembling, lifting and connecting the steel boxes, it also could have been anticipated that tight control and coordination was of the essence. Quite obviously, the settlement between LYCA and WSC achieved the opposite. Instead of neutralizing the negative impact of an already existing fault line the separation of competences and responsibilities between WSC and JHC aggravated the risk of insufficient coordination and control.

In this very sense, splitting up competences and control for what was a coherent and integral segment of the entire construction process was already risky and unwise enough. However, the selection of JHC as substitute contractor for the erection of the steel spans was an act of blunder in its own right. After all, JHC was a local corporation and the Lower Yarra Crossing Authority was a hybrid institution vested with regulatory powers and acting as quasi-public authority although it consisted exclusively of representatives of local businesses. The chief executive officer of JHC, Mr. C. V. Holland, was a successful Melbourne businessman and, unlike the representatives of WSC as a Dutch-based firm, socially well embedded in the local business community. Unlike WSC, however, JHC had no experience with steelworks, let alone with the type of sophisticated assembling and erection processes envisaged in the case of the West Gate

\footnotetext{
${ }^{17}$ Royal Commission, 16.
}

${ }^{18}$ Ibid. 
Bridge. As the Royal Commission put it, "JHC's experience with the assembly and erection of steelwork was limited", only to make the real issue crystal clear:

No operation of this size and complexity of the West Gate Bridge steel structure had ever been undertaken by that company $[=\mathrm{JHC}]$. Consequently, the ability of their personnel to handle a project of such magnitude remained untested and conjectural. (...) The expertise of the Holland group lay more with concrete than steel, and its management recognized that the nature of the design of the steelwork in this bridge was a field in which it had no experience. ${ }^{19}$

To make things worse and to dilute control and responsibility even more, the task to be assumed by JHC was limited to the mere physical erection of the steelwork while JHC "would have no responsibility for engineering decisions relating to final or erection stresses in the bridge" 20 which was mildly characterized by the Royal Commission with the wording that "the relative inexperience of JHC influenced them [JHC management] to seek, and the Authority [LYCA] to grant, some limitation of the usual the contractor's responsibility". ${ }^{21}$

The core of the matter was that LYCA as the supervising and ultimately responsible institution had tasked $\mathrm{JHC}$ with a job the firm was unfit to do. The entire new arrangement between LYCA and JHC was laid down in a new contract signed 10 July 1970 and labeled "Contract E". Although the division of labor between WSC as the previous main contractor for the steelworks and JHC as the new substitute contractor had already started in late March 1970, the peculiarities and the unusual character of the new contractual arrangement were reflected, according to the Royal Commission, in the fact that "the legal advisers of both parties [LYCA, $\mathrm{JHC}$ ] experienced considerable difficulty in arriving at a mutually acceptable form of contract". ${ }^{22}$

The Royal Commission, in its report, was reluctant to address the obvious asymmetry in negotiation leverage that clearly disadvantaged LYCA. ${ }^{23}$ While LYCA could not afford to abort negotiations on a new contract on

\footnotetext{
${ }^{19}$ Royal Commission, 80 .

${ }^{20}$ Ibid.

${ }^{21}$ Royal Commission, 81 .

${ }^{22}$ Ibid.

${ }^{23}$ Ibid.
} 
the steelworks that were underway but still incomplete, JHC had no incentive whatsoever to assume responsibility beyond the immediate physical task of erecting this steelwork of the bridge. LYCA's General Manager, C. V. Wilson, admitted before the Royal Commission that "very little responsibility could be placed" on JHC and that he and his consultants "were all well aware of it while negotiations were taking place". ${ }^{24}$

As a consequence, LYCA accepted an organizational and contractual arrangement that inevitably increased risks at the expense of sound and safe completion of the works while at the same time reducing the capacity of risk management. "Contract E" signed 10 July 1970 purposefully limited the responsibility of JHC as the contractor assuming the most complex and ambitious task of the entire construction of the bridge. At the same time, it was acknowledged that JHC itself had neither expertise nor experience with the nature of construction it was tasked with and, yet, was contractually exempted from liability. This arrangement virtually eliminated what should have mattered most which was tight coordination and coherent control of a technically complex construction and erection process. The Royal Commission was plausibly conjecturing about the underlying incentives:

In the climate of urgency which prevailed, the willingness of JHC to undertake work immediately, without the inevitable interruption which would occur if any other contractor was appointed must have been an over-riding consideration for the Authority [= LYCA $].{ }^{25}$

The very fact that JHC had successfully rejected any responsibility for engineering decisions beyond the mere physical task of erecting the steelwork implied a crucial role of FF \& $\mathrm{P}$ in assuming precisely that part of tasks and responsibilities. FF \& P was represented in Melbourne and on the construction site by a Resident Engineer, Jack Hindshaw. It should have been clear from the very outset, however, that a related division of labor between JHC and FF \& P in addition to that between JHC and WSC was virtually unacceptable. After all, every single step of erecting the steelwork could trigger erection stress in the bridge so that separating the responsibility for erecting the steelwork from the responsibility for the diagnosis and elimination of erection stress required constant

\footnotetext{
${ }^{24}$ Ibid.

${ }^{25}$ Royal Commission, 82 .
} 
communication and coordination between two independent firms. Not surprisingly, as the Royal Commission stated, the attempt "to define the roles of the FF \& P staff and JHC engineers led to a confusion that was disastrous". ${ }^{26}$

It turned out that London-based FF \& P, represented in Melbourne in early 1970 temporarily by one of its most senior and influential partners, Sir G. Roberts, had not the slightest inclination to do justice to the highly unusual arrangement laid down in the agreement between LYCA and JHC. Roberts' unwillingness was just the flipside of JHC's attitude in the negotiations with LYCA: While JHC had every reason to reject responsibility for issues of structural engineering that were beyond its expertise and professional competence, Roberts and FF \& P were not willing to accept responsibility for the solution of problems originating from the works of JHC without having any say about their execution. Again, this could have been anticipated since the very "confusion" deplored by the Royal Commission was implied in the arrangement between LYCA and JHC resulting in "Contract E" of 10 July 1970. It could not come as a surprise that neither JHC nor FF \& P wanted to assume responsibility for decisions and consequences beyond their respective control.

\subsubsection{Predictable Rivalries and Quarrels}

It was not surprising either that the immediate consequences of the "confusion" referred to by the Royal Commission had to be borne by the representatives of FF \& P and JHC on the construction site itself. Frictions and conflicts were unavoidable. While the Royal Commission was lenient as far as LYCA and the fundamental decision to split up the respective responsibility for the steelworks was concerned it was not reluctant at all to characterize the attitude of FF \& P and its Resident Engineer, Jack Hindshaw (who had perished in the disaster of 15 October 1970) in critical and somewhat sarcastic terms:

Hindshaw's communication to his superiors in London disclose his bewilderment and his attempts to rationalize the situation. His work-to-rule practice and somewhat pin-pricking attitude to the JHC staff created from them a natural reaction. This unhappy state of affairs had an inevitable effect on

${ }^{26}$ Ibid. 
the work of construction and created a climate in which the probability of error in judgement was greatly increased. ${ }^{27}$

Yet, it was another euphemism when the Royal Commission stated that Hindshaw attempted "to rationalize the situation" ${ }^{28}$ Rather, he was facing an unsolvable dilemma. Hindshaw had to cope with a situation in which he, on the one hand, had to act just as a consultant and, on the other hand, was expected to take managerial decisions. Problem solving on the construction site would have required clear-cut competences and a seamless chain of command-which was exactly what the arrangement between LYCA and JHC failed to ensure. Hindshaw was thus tasked with the proverbial mission impossible.

The consequence was a constant quarrel between FF \& P and JHC engineers. The entire construction crew was at times, it seems, more concerned with its internal affairs than with the construction itself. The Royal Commission, in its report, lamented about this state of affairs and stated, "all this confusion and difficulty could and should have been quite easily avoided, had the increased responsibility of FF\& P been clearly defined in the first place". ${ }^{29}$ But, again, the Commission missed the point in ignoring that the lack of clarity was the inevitable consequence of appointing JHC as a substitute contractor for the steelworks of the West Gate Bridge despite the openly admitted lack of competence and expertise in this domain. What the Royal Commission characterized as "unhappy circumstances" 30 implied that "neither the FF \& P site staff nor the JHC engineers knew where they stood, nor for that matter did the management of either body". ${ }^{31}$ And it continued that "this situation of doubt and misunderstanding had extremely serious consequences, as it created the circumstances in which the actions which were the immediate cause of the failure and collapse of span 10-11 were able to take place." 32

\footnotetext{
${ }^{27}$ Ibid.

${ }^{28}$ Ibid.

${ }^{29} \mathrm{Ibid}$

${ }^{30} \mathrm{Ibid}$.

${ }^{31}$ Ibid.

${ }^{32}$ Ibid.
} 


\subsubsection{Losing Control: The Struggle of the Lower Yarra Crossing Authority}

Still, the question remained, also in the perception of the Royal Commission, why The Lower Yarra Crossing Authority itself had not taken better care of the implementation of the new contractual arrangement with JHC in an effort to straighten out the emerging calamities of control and coordination. ${ }^{33}$ As usual under similar circumstances, LYCA had no own engineering staff directly involved in the design and erection of the bridge. Its task was to select consulting engineers, participating in the decision about the design of the bridge and to exercise the general overview over the construction process, especially in terms of implementing and, if necessary, modifying or amending the existing contractual arrangements and coordinating the activity of the various consultants and contractors.

Although LYCA had been constituted by private enterprises it had experienced officials at its disposal. Especially LYCA's General Manager, C.A. Wilson, was not only a professional engineer himself "with considerable experience of bridge design" 34 but also a former senior design engineer in the Bridge Division of the Country Roads Board (CRB) of the state of Victoria. The fact, however, that Wilson was a trained engineer with considerable experience in bridge design had ambiguous consequences for the way control and oversight was exercised by LYCA. While Wilson kept a sharp eye on engineering details, issues of steel quality and potential brittle in particular, he, according to the assessment of the Royal Commission, neglected the requirements of coordination and conflict management, especially when related problems intensified due to the delay of the steelworks at the replacement of WSC by JHC. ${ }^{35}$ To a large extent, however, the problems Wilson as the undisputed key-figure of LYCA was facing were enrooted in the very governance structure of planning, designing and constructing the West Gate Bridge. And, after all, LYCA itself and, necessarily, Wilson in person had been directly involved in creating that structure.

The logic of the arrangement was the delegation of supervision and control to FF \& P in partnership with Maunsell as joint consultants. Only Maunsell was located in Melbourne while FF \& $\mathrm{P}$ headquarters was

\footnotetext{
${ }^{33}$ Royal Commission, 83-85.

${ }^{34}$ Royal Commission, 84.

${ }^{35}$ Royal Commission, 84.
} 
located in London. That FF \& P in far-away London became part of the control and supervision structure at all was due to the fact that Maunsell itself had declared its lack of experience with bridge building projects of the envisaged and required scale and size while FF \& P was a world-wide renowned consultancy firm for precisely this kind of construction. But FF \& P had no permanent senior representative in Melbourne, much to the dismay of LYCA. ${ }^{36} \mathrm{FF} \&$ P's key figure in Melbourne and on the construction site throughout the entire construction period remained Resident Engineer Jack Hindshaw. With him LYCA and, in reality, Wilson in person interacted directly and, according to the evidence, an intense conflict between the two emerged when the substantial delay of the steelworks to be performed by WSC became apparent. ${ }^{37}$ The Royal Commission, in its report, hinted that Wilson was an unbridled person who easily lost temper so that he, according to all likelihood, also lacked the necessary patience and diplomatic skill required especially under the condition of a fragmented control and governance structure that made intensified coordination and conflict management even more indispensable. ${ }^{38}$

So what the Royal Commission suggested was that Wilson's selective expertise which was primarily focused on a narrow segment of the structural engineering together with his personal temperament rather aggravated than mitigated the undesirable consequences of an ill-structured system of control and supervision. At any rate, the Royal Commission left no doubt that the atmosphere between LYCA and Wilson in person on the one hand and FF \& P and also JHC engineers on the other hand was poisoned: "Both the FF \& P and JHC engineers on the site appear to have regarded Wilson as something as a 'bogey man', particularly Hindshaw, who claimed that Wilson had 'torn strips of him'". ${ }^{39}$

The Commission nonetheless conceded that "he [Wilson] was in a most unenviable position, with responsibility for a great and complex project which almost from the first encountered difficulties" and that with

${ }^{36}$ Royal Commission, 85.

${ }^{37}$ Ibid.

${ }^{38}$ In the words of the Royal Commission: "In one of Hindshaw's personal reports to London he described Wilson as being extremely antagonistic to FF \& P claiming that the failure of WSC was due to lack of care and diligence by FF \& P and threatening to sue them for $\$ 1,000,000$. A perusal of the early correspondence shows that from the beginning down to a week or so before the disaster there was a continuous complaint by Wilson and resentment by FF \& P."-Royal Commission, 84.

${ }^{39}$ Ibid. 
"regard to the lack of progress, as well as many other defaults and errors made by the engineers and contractors the attitude of the Authority [LYCA] was quite understandable". ${ }^{40}$ While the Commission one more time shed a mild light especially on the attitude of LYCA and its leadership it nonetheless pointed to one crucial aspect in stating that "fundamental to the whole sorry situation was the constant sense of urgency and pressure to complete the construction within specified times." 41 The time pressure was, as we saw, created and aggravated by the substantial delay of the steelworks to be completed by WSC. But the Commission also pointed to the undesirable consequences of the particular institutional character of LYCA which was a legal entity composed of private businesses working with borrowed capital and therefore acting under the particular pressure of return of investment expectations. ${ }^{42}$ "In a number of instances," the Commission stated, "the burning desire for speed resulted in quick, illconsidered decisions which brought about trouble, difficulty and delay," and underlined, "that this climate of urgency and pressure tended to lower morale, and in fact directly caused some of the more serious errors of judgment". ${ }^{43}$

The most serious consequence of this "sorry situation", as the Royal Commission put it, ${ }^{44}$ was that LYCA and Wilson in person witheld crucial information about the overall safety of the bridge design that had been put forward by WSC and should have been brought to the attention of its successor as a substitute contractor for the completion of the steelworks. As a matter of fact, WSC's Chief Engineer and Senior Representative in Melbourne, Gerit Hardenberg, back in the second half of 1969, had had a dispute with FF \& P about appropriate measurement of stress impact on the steel construction, bending stress and buckling stress in particular. ${ }^{45}$ This and the fact that FF \& $\mathrm{P}$ was slow in responding to inquiries and correspondence in this matter was part of the protracted disputes and difficulties that contributed to the substantial delay of the completion of the steelworks initially assigned to WSC. Obviously, the subject of bending

\footnotetext{
${ }^{40}$ Ibid.

${ }^{41}$ Royal Commission, 85 .

42 "The financial consequences of any delay were serious to an organization working on borrowed capital - and a degree of pressure to reach completion on time is understandable and even praiseworthy."-Royal Commission, 85 .

${ }^{43}$ Ibid.

${ }^{44}$ Ibid.

${ }^{45}$ Royal Commission, 86-87.
} 
stress and resulting buckling was of immediate and crucial importance for the overall stability and safety of the bridge, a fact that was tragically corroborated by the collapse of 15 October 1970 .

Wilson as general director of LYCA whose prime concern should have been the ultimate safety of the bridge "was aware of the views of Hardenberg that the structure could have been unsafe" and was himself "still [i.e., in March 1970] concerned about the adequacy of the design, to the point where he had sought a complete re-checking by FF \& P" ${ }^{46}$ However, Wilson withheld this information to JHC when the negotiations between LYCA and JHC were underway in the attempt to win over JHC as a substitute contractor replacing WSC. ${ }^{47}$ Withholding essential information about doubts and disputes concerning the ultimate stability and safety of the bridge was a breach of trust committed by LYCA and its director general vis-à-vis the new contractor. JHC was left in the dark about already diagnosed risk zones affecting the stability of the steelworks and, thus, the overall safety of the bridge. This was even more serious an omission since JHC had no expertise nor experience with the steelwork part of bridge constructions of this scale, a fact that was perfectly known to LYCA and Wilson in person since JHC, when negotiating a new contract with LYCA, later on known as Contract E, successfully rejected any responsibility for steelwork design issues and the solution of resulting problems.

As a result, the Royal Commission concluded, "the new contractor [JHC] was about to enter upon the work without the necessary information enabling him to make calculations of safety factors" and it pointed to the fact that indeed "the form of the contract did not require him [JHC] to be responsible for such calculations". In sum, the Commission stated "we feel that the Authority [LYCA] had at least a clear moral obligation to inform JHC fully of the doubts that were currently entertained". ${ }^{48}$

\subsubsection{Improper Consultancy}

The lack of experience in steelworks of JHC as the substitute contractor replacing WSC and the fact that, consequently, the new contract (Contract E), ultimately signed after protracted negotiations on 10 July 1970,

\footnotetext{
${ }^{46}$ Royal Commission, 85 .

${ }^{47}$ Ibid.

${ }^{48}$ Ibid.
} 
exempted JHC from any responsibility for issues of structural engineering of the steelworks and necessary corrections implied, in turn, the sole responsibility and pivotal role of FF \& P. FF \& P was, however, ill-equipped to assume this crucial task on organizational grounds alone. Most of the necessary engineering calculations and, above all, key decisions concerning structural engineering were made in London. Much to the dismay of LYCA and its contractors WSC and JHC, no senior FF \& P representative took residence in Melbourne. ${ }^{49}$ The discrepancy between the degree and complexity of FF \& P's responsibility and FF \& P's lack of commitment and diligence was obvious. It was also perceived as such by LYCA—as we saw, Wilson in particular-and JHC. As the Royal Commission found out and stated in its report, "even the FF \& P staff on the site had occasion to complain to the London office, chiefly on the ground that their urgent requests for instruction or information were answered only after long delays and repeated requests, or simply ignored." 50

Quite naturally, LYCA and Wilson in person were of the opinion that a more senior FF \& P officer, maybe a Partner of the consultancy firm, with continuous residence in Melbourne could mitigate those problems through a better standing vis-à-vis the London office and extended discretionary leeway in assuming his responsibilities in Melbourne but related initiatives were to no avail. ${ }^{51} \mathrm{FF} \& \mathrm{P}$ "did not send out a senior man who could handle an unusual situation" but in April 1970 they did send out three more engineers, Jack Hindshaw, C. V. J. Simpson and David Ward. ${ }^{52}$ Hindshaw became Resident Engineer replacing D. F. McIntosh who was made Resident Engineer for the fabrication and box-assembly work and returned to England in September 1970.

None of the four FF \& $\mathrm{P}$ engineers, including the senior figure Hindshaw, had personal experience with the erection of any major steel bridge. ${ }^{53}$ What is more, FF \& P engineer's office was on the east bank of the Lower Yarra River while on-site inspections on the west bank were left to occasional visits by the junior and necessarily least experienced crew members. Hindshaw himself as, after all, Resident Engineer and most senior FF \& P representative reportedly never truly inspected what was

\footnotetext{
${ }^{49}$ Royal Commission, 86.

${ }^{50}$ Ibid.

${ }^{51}$ Ibid.

${ }^{52}$ Ibid.

${ }^{53}$ Royal Commission, 87.
} 
going on the west side. The Royal Commission noted that there was "evidence that on one occasion seven weeks elapsed without Hindshaw visiting the west side and, according to [JHC section engineer] Tracy's diary, even then he "got no further than the office".${ }^{54}$ In sum, the Commission stated, "having failed to provide a senior engineer capable of fundamental professional decisions, the London partners left the relatively junior engineers on the site without sufficient communication." 55 The negative consequences of this constellation materialized when serious problems of structural engineering did indeed occur on the west side of the bridge in September 1970.

\subsubsection{Evaporating Responsibility and a 'Climate of Confusion'}

In general, both the organizational and the contractual arrangements between LYCA and FF \& P were, in combination with the huge concessions LYCA had made to JHC as immediate contractor for the steelworks of the West Gate Bridge, a syndrome of risk zones undermining proper and diligent control and responsible action. It was therefore, a comprehensible but futile and even helpless conclusion when the Royal Commission, in its report, summarized the conditions with a battery of counterfactuals:

If the resident engineer had been properly and fully briefed as to his duties on site; if he had been required to submit regular full fortnightly reports to London, setting out the progress made, any delays and reasons for them, condition of steelwork, lines, levels \&c., labour problems, any unexpected events; and if each report had been replied to at once by a senior engineer in London, charged with responsibility for the contract-all the errors that were committed might well have been avoided. ${ }^{56}$

However: If all the actors involved would have been this diligent and mindful, the whole complex and conflict-ridden arrangement between them would probably not have emerged in the first place. What contributed to the circumstances was that profound frictions and conflicts existed even between the joint consultants, Maunsell and FF \& P. This is, at first glance, particularly counterintuitive since Maunsell had suggested to

\footnotetext{
${ }^{54}$ Ibid.

${ }^{55}$ Ibid.

${ }^{56}$ Royal Commission, 88 .
} 
involve FF \& P due to its outstanding reputation especially with large bridge construction projects. Officially, Maunsell and FF \& P were to act as "joint consultants" but the division of labor between them was yet another example of the complexity, overlapping competences and diluted responsibilities. While Maunsell was responsible for all contracts other than for steel spans, FF \& P was responsible for the design of the steelwork and for supplying engineering staff for general supervision and control of the entire construction. As far as the steelwork itself was concerned, Maunsell acted as sole representative of the joint consultants in Melbourne and had also to control all administrative matters while FF \& P controlled the technical side. ${ }^{57}$ Accordingly, FF \& P's Resident Engineer for the steelwork reported to of a senior Maunsell partner, E. Miles Birkett, but only for administrative purposes while technical matters had to be handled in cooperation and communication with FF \& P headquarters in London. FF \& P London was tasked with the scrutiny and approval of the actual contractors'-WSC and JHC-working drawings and erection scheme drawings for which the necessary technical conferences were to be held with WSC in London or Utrecht. ${ }^{58}$

Not surprisingly, a similar pattern of distrust and rivalry emerged out of this as between the contractors, LYCA and FF \& P. One reason was, again, FF \& P's "habit of not answering letters or telex messages and generally being the opposite to forthcoming with information quite legitimately sought" ${ }^{59}$ Moreover, there was blunt rivalry involved. As it turned out in the course of the Royal Commission's investigations, Maunsell's senior partner Birkett had actively discouraged FF \& P headquarters in London to follow the request of LYCA to have a senior partner of FF \& P permanently on site in Melbourne. For Birkett, a senior representative of Maunsell, this was apparently a question of prestige since it could be anticipated that his own role as sole representative of joint consultants would have been much more limited with a senior FF \& P partner permanently present in Melbourne. Conversely, FF \& P's Resident Engineer, Hindshaw, when communicating with London, was not only constantly complaining about Maunsell and Birkett in person but also "deliberately by-passing Maunsell". ${ }^{60}$ The separation between administrative and technical matters,

\footnotetext{
${ }^{57}$ Ibid.

${ }^{58}$ Ibid.

${ }^{59}$ Ibid.

${ }^{60}$ Ibid.
} 
one to be handled by Maunsell and one by FF \& P, was artificial and almost unmanageable which was just another source of arguments and related inefficiencies. ${ }^{61}$ The Royal Commission concluded:

There are many other incidents revealing an unhappy and uneasy relationship between the joint consultants which it would be merely tedious to record. Sufficient to say that this disagreement added to the climate of confusion which prevailed throughout the period of construction. ${ }^{62}$

As a consequence of Contract E ultimately signed on 10 July 1970, JHC took over the steelworks of the West Gate Bridge as a substitute contractor succeeding WSC. JHC's project manager in charge, T.R. Nixon, an experienced construction engineer and project manager, had been working with the Country Roads Board (CRB) of the state of Victoria after college graduation in the early 1950s before joining JHC in 1958 where he was primarily concerned with the management of roads and roadway bridges. The fact that $\mathrm{JHC}$ in general had by its own admission no experience or substantial expertise in steelworks should have implied efforts of compensation and an elevated level of diligence and compliance. According to the findings of the Royal Commission, this was by no means the case. Nixon as the project manager was required to attend "numbers of meetings in Sydney, Hobart and elsewhere and also engineering symposia and other meetings". ${ }^{63}$ Already in formal terms, the Royal Commission stated, this was a breach of JHC's contract. ${ }^{64}$ The technical problems of structural engineering that soon turned out to be particularly challenging were left to junior engineers of the JHC team. Services and expert knowledge of senior engineers of WSC as the firm initially in charge of the steelworks now in the hands of JHC were not requested. ${ }^{65}$ In general, according to the judgment of the Royal Commission, "there was lamentably poor output by the labour force under JHC, particularly on the west side" of the bridge (where the disaster of 15 October 1970 occurred). ${ }^{66}$ The Royal Commission left no doubt that "some part of the trouble was caused by

\footnotetext{
${ }^{61}$ Ibid.

${ }^{62}$ Ibid.

${ }^{63}$ Royal Commission, 89.

${ }^{64}$ Ibid.

${ }^{65}$ Ibid.

${ }^{66}$ Ibid.
} 
the inadequacy of the JHC staff, who were lacking in steel erection experience sufficient for the work they had to do on the contract" ${ }^{67}$

Not surprisingly, frictions and conflicts emerged between FF \& P's Resident Engineer, Jack Hindshaw, and JHC engineers. ${ }^{68}$ What initially had been an abstract and objective conflict of interest between JHC and FF \& P as far as jurisdiction and responsibility were concerned turned out to be a substantial problem on the construction site itself. Those disputes, just to remember, had their roots in the fact that JHC staff "were lacking in steel erection experience sufficient for the work they had to do on the contract" ${ }^{69}$ For that very reason, JHC, when negotiating with LYCA on a new contract (Contract E) through which JHC ultimately stepped in as a substitute contractor replacing WSC, had successfully insisted on limiting its own responsibilities to the mere physical part of the steel erection leaving aside the control of overall structural engineering, a task to be assumed by FF \& P. FF \& P, in turn, was all but enthusiastic about this division of labor since responsibility for structural engineering implied being liable for decisions and omissions in the process of the steel erection that, by definition of the contract, remained beyond the control of FF \& P. As a consequence, the relationship between JHC and FF \& P was tainted from the very outset. "There were constant arguments between the JHC management and the FF \& P organization as well as between the consultants' engineers and the contractors' engineers on the site." ${ }^{" 70}$ The result was organized irresponsibility in a literal sense. ${ }^{71}$ The Royal Commission came to the following conclusion:

The question of responsibility was still unresolved on $15^{\text {th }}$ October, when the span 10-11 collapsed. Leaving this question unresolved considerably reduced the effectiveness of the resident engineer, Hindshaw, and endangered the whole project by tending to create an atmosphere in which cooperation between the engineers for the consultants and engineers for the

${ }^{67}$ Ibid.

68 "From the time JHC began to work on steel spans, there were constant arguments between the JHC management and the FF \& P organization as well as between the consultants' [FF \& P] engineers and the contractors' [JHC] engineers on the site."-Ibid.

${ }^{69}$ Ibid.

${ }^{70}$ Ibid.

${ }^{71}$ The report of the Royal Commission mentions several examples of non-decisions and responsibilities being shifted back and forth between JHC and FF \& P, cf. Ibid., 89-90. 
contractor was difficult. Several witnesses spoke of a state bordering on chaos prevailing on the west side. ${ }^{72}$

The west side of the bridge referred to in the remark of the Commission was where span 10-11 was located. The Royal Commission also stated unmistakably that it deemed the "chaos" on the west side the decisive factor for sloppiness and inaccuracy that occurred in the process of bolting up the steel boxes as the core-components of the girders of the bridge span:

There are reports of large groups of men wandering aimlessly around in the middle of the morning with nothing to do; of other men attempting to perform impossible operations when trying to bring parts into line for bolting up. Bolting up on that side appears to have been done without system, putting in bolts where they would go, with little regard for how later ones could be placed. Reaming of bolts was in consequence widespread. In some cases, the over-enlarging of the holes by reaming was so bad that special washer plates had to be provided under the bolt heads. ${ }^{73}$

In its own conclusion, the Royal Commission stated, "Error begat error, and the events which led to the disaster moved with the inevitability of a Greek tragedy." ${ }^{\prime 4}$ There is good reason to disagree with the last part of this conclusion. Of course, the acts and omissions of those involved were tragic but, according to the Commission's own findings, they were not inevitable. The institutional arrangement of public oversight could and should have been different, the contracts between the Lower Yarra Crossing Authority could and should have secured the coherence of expertise, competence, jurisdiction and control of consultants and contractors. Remaining fault-lines and frictions within a necessarily division of labor-based system of construction and control could and should have been neutralized by capable and mindful senior managers.

The logic of inevitability referred to by the Royal Commission does apply, however, to the consequences of neglect and lack of mindfulness that remained unaddressed and uncorrected even when the first signs of a potentially fateful path dependency had already occurred. The Commission stated quite convincingly that avoiding the disaster would not have required any particularly high standard of perfection. Just sticking to a

\footnotetext{
${ }^{72}$ Royal Commission, 90.

${ }^{73}$ Ibid.

${ }^{74}$ Royal Commission, 97.
} 
moderate "standard of reasonable competence to be expected from men holding themselves out as competent professionals" would have sufficed. ${ }^{75}$ Which makes the failure of consultants and contractors with an outstanding professional reputation to meet those standards even more counterintuitive.

\subsection{The Disaster in the Making}

As a consequence of the chosen technique of assembling and lifting two separate halves of the box-girder based spans, two half-spans of every segment had to be joined together once lifted into position at a height of 170 feet above ground level. While lifting the entire half spans into position was certainly challenging since it had to be performed by using jacking straps and rolling beams, the accuracy of joining the two halves turned out to be the tricky part. The stability of the construction depended on the accuracy of the assembling procedure on the ground and that the core-parts, the boxes, had to have exactly identical size and shape since otherwise difficult and time-consuming corrections would be unavoidable.

The Royal Commission stressed that the chosen method of the erection of the bridge spans was entirely unique and that it had found "no evidence ... that this method of erection had ever been attempted before, anywhere in the world, under conditions similar to those prevailing at the West Gate Bridge." "6 Still, the Commission underlined, the method could have been "successfully adopted, provided that very careful forethought had been given to dealing adequately with all the potential difficulties". ${ }^{77}$ Those difficulties, however, turned out to be dramatic but they remained unchecked due to absence of coherent control and mindful management.

Serious issues became apparent when a first girder of eight half boxes was to be lifted at the north half of the east Side of the bridge under construction designed to form span $14-15 .{ }^{78}$ When the pre-assembled span was lifted to be put in position, significant instability of the projecting flange plates was observed. That instability caused a severe buckle at the

${ }^{75}$ Ibid.

${ }^{76}$ Royal Commission, 16.

${ }^{77}$ Ibid.

${ }^{78}$ The report of the Royal Commission does not mention the exact date of the incidence. Since the report, on page 21 , does mention a note written by FF \& P engineer McIntosh to JHC of April 1970 referring to the problems at span 14-15 the incidence itself probably occurred in early 1970. 
splice between boxes 4 and 5 of a row of eight boxes forming span 14-15. The estimated depth of the buckle was 15 inches thus representing a sharp kink which was beyond the elastic limit of the construction, a fact that was nonetheless not recognized by the engineers on the site. ${ }^{79}$ Buckles of minor dimensions affecting the upper cover flat were usually pressed out using specially long bolts between the cover flat and the robust substructure underneath. Once this work was completed the long bolts were removed and replaced with the final bolts with a particular friction grip. This procedure could be carried out for most part of the northern half of the 14-15 span thus straightening out most of the buckles on the plate edge of the north boxes.

However, precisely because the operation of straightening out the buckles had been successful for most part of the 14-15 span, for a remaining short section around box 5 there was no flexibility left. It was therefore decided to undo the transverse seam of the north inner panel in an attempt to regain flexibility of the construction allowing for small movements between plates in the hope that the movement itself would be enough to straighten also the remaining buckle. For that purpose, bolts were removed that had connected the north and the south half of boxes 4 and 5 and, simultaneously, from the joint between boxes 5 and $6 .{ }^{80}$ Since the removal of the bolts connecting box 5 to neighboring boxes 4 and 6 resulted in new flexibility of box 5 the operation "had the desired effect of flattening out the remaining bulge". ${ }^{81}$ Subsequently, new bolts reconnecting box 5 to boxes 4 and 6 were re-entered. ${ }^{82}$

While the operation of flattening out the buckles on the covering plates-i.e., the surface of the construction-was apparently successful it was diagnosed by the Royal Commission as "a regrettable necessity". ${ }^{83}$ Moreover, it turned out to be the epitome of successful failure. ${ }^{84}$ The successful coping with the buckle issue on the east side of the bridge gave the engineers in charge the false impression that the unbolting and re-bolting procedure was an appropriate and relatively easy technique to apply. So the very same procedure was repeated on the west side of the bridge in

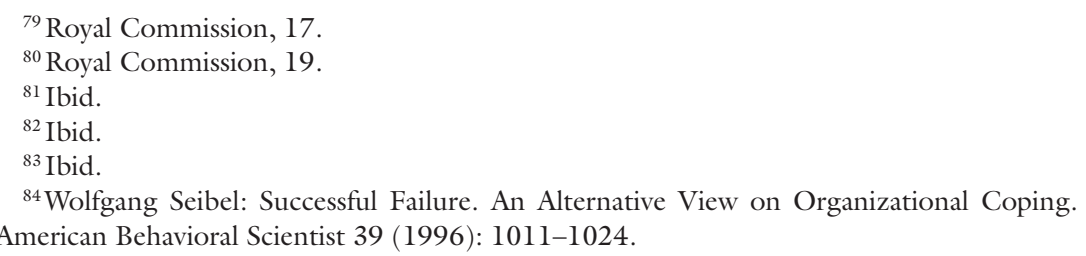


October 1970 when buckles at span 10-11 had occurred. The Royal Commission commented:

Having successfully dealt with the buckle on the east side, the engineers were reasonably confident of their ability to handle the buckle on the west side; a confidence that was fatally misplaced. ${ }^{85}$

The consequences of misplaced confidence started to evolve when the two half girders (the substructure of the span) on the west side of the bridge concerning span 10-11 had been brought into position up in the air and were to be connected to each other. It turned out that a camber difference of about $4 \frac{1}{1} 2$ inches existed between the two halves of the span. Engineers of the contractor in charge, John Holland Constructions Proprietary Ltd. (JHC), proposed to use kentledge to push down the higher half span, the north part, to equalize its level relative to its south counterpart. For that purpose, ten blocks of concrete that happened to be onsite anyway, each with a weight of eight metric tons, were positioned as a concentrated lot in the middle of span 10-11.

The loading of the kentledge was completed on 5 September 1970. The next day, 6 September, a major downward buckle had developed more or less in the middle of the span at the splice between box 4 and box 5 . At that time, there was still a one inch camber difference between the northern and the southern part of span 10-11. Accordingly, the diaphragms supposed to connect the two parts could not be bolted. That gap was eliminated by jacks pushing down on the north half and pushing upwards on the south half. As a result of that operation, almost all connections of the inner diaphragms could be made with the exception of those at box 4 where a transverse beam to which the diaphragm should have been bolted was too much displaced by the buckle. Since all other diaphragms were fully bolted and even the diaphragm at box 4 was bolted except for the one connection to the transverse beam the kentledge was removed since it had basically done its job.

With the removal of the kentledge the entire bending stress had necessarily to be borne by the core structure of the girders buttressing the two half spans that in the meanwhile had been bolted together. Since no sound calculation existed, the amount of stress and the consequences for the overall stability of the structural design was not subject to accurate

${ }^{85}$ Royal Commission, 19. 
assessment. ${ }^{86}$ The successful bolting procedure connecting the two half spans on the west side had no effect on the buckle at the splice between boxes 4 and 5 on the northern part of the span between pier 10 and pier 11 which itself was the consequence of the added kentledge. The buckle clearly indicated a structural damage and a reduced margin of safety of the entire bridge. ${ }^{87}$

The Resident Engineer of the main consultancy firm supervising and basically running the operation, Jack Hindshaw of Freeman, Fox and Partners (FF \& P), was nonetheless confident that the buckle could be relatively easily eliminated according to the method used months before on the east side of the bridge. After all, that method was to increase local elasticity of the girder structure through unbolting and, thus, isolating an individual box which in fact had made it possible to flatten out the buckle that had developed there at span 14-15. Applying the same method on the west side to span 10-11 implied to take out the bolts at the splice between box 4 and box 5 of span 10-11. On the west side, however, the longitudinal splices between the half spans were not completed yet at this point. As the Royal Commission stated in its report, even

a most rudimentary assessment let alone familiar with stress analysis would ... have recognized that undoing the bolts before the longitudinal splices between the half spans were complete would create a dangerous 'notch effect' with its associated stress concentration at the head of the notch. ${ }^{88}$ The possibility of its producing calamitous failure was not to be dismissed without serious consideration. ${ }^{89}$

"Serious consideration" did not take place, however. If FF \& P's Resident Engineer would have undertaken it, "he should have instantly vetoed any suggestion of taking out the bolts". ${ }^{90}$ For several weeks prior to 15 October 1970 the buckle issue remained unaddressed though since there was consensus among the engineers in charge to wait until the last box of span 10-11 (box 9) had been completed. However, on 13 October 1970 Hindshaw changed his mind and instructed the section engineer in

\footnotetext{
${ }^{86}$ Ibid.

${ }^{87}$ Ibid.

${ }^{88}$ Royal Commission, 24.

${ }^{89}$ Ibid.

${ }^{90}$ Ibid.
} 
charge to have the buckle eliminated. ${ }^{91}$ The bolts at the splice between box 4 and box 5 were removed on a step-by-step basis-no more than 6 or 8 bolts at a time-in order to allow for thorough examination that no undesirable reaction of the structure would occur. ${ }^{92}$

The work of unbolting the splice between box 4 and box 5 of span 10-11 on the west side of the West Gate Bridge started at about 8:30 a.m. on 15 October 1970. When 30 bolts had been removed from the box 5 side of the splice and seven bolts from the box 4 side of the splice "a dramatic change took place" $" 93$ since the initial buckle spread into two outer flange plates. This and the fact that witnesses confirmed that they felt "a gentle settlement of the north half span of the bridge", implied, according to the assessment of the Royal Commission, that "from that time onwards the north half span had inadequate strength to sustain its own weight and only survived because it was able to bear down on to the south half through the interconnected transverse diaphragms". ${ }^{94}$ According to the Commission, "the margin of safety in the south half span was not such that the entire dead load of the north half span could be borne in addition to its own self weight". ${ }^{95}$

Still, it took 50 more minutes after the spreading of the buckle into the outer flange plates until the total collapse of span 10-11. In the meantime, a frenzy of hectic work had started in the attempt of getting the bolts back into place. The rebolting was even going quite well which might have created confidence that the situation was not really deteriorating. ${ }^{96}$ That Hindshaw who together with FF \& P's site engineer P. J. F. Crossley had meanwhile rushed to the site of the incident was nonetheless gravely concerned is indicated by the fact that he telephoned chief engineer Hardenberg of the meanwhile marginalized WSC whose expertise in the steelwork part of the construction was much bigger than the one of JHC, the firm officially in charge. Hindshaw asked Hardenberg to come over to the location of the incident. However, "almost immediately after that telephone conversation at 11:50am span 10-11 collapsed". ${ }^{97}$ Hindshaw himself was among the 35 men who died in the disaster (Illustration 2.2).

\footnotetext{
${ }^{91}$ Ibid.

${ }^{92}$ Royal Commission, 25.

${ }^{93}$ Royal Commission, 26.

${ }^{94}$ Ibid.

${ }^{95}$ Ibid.

${ }^{96}$ Ibid.

${ }^{97}$ Ibid.
} 


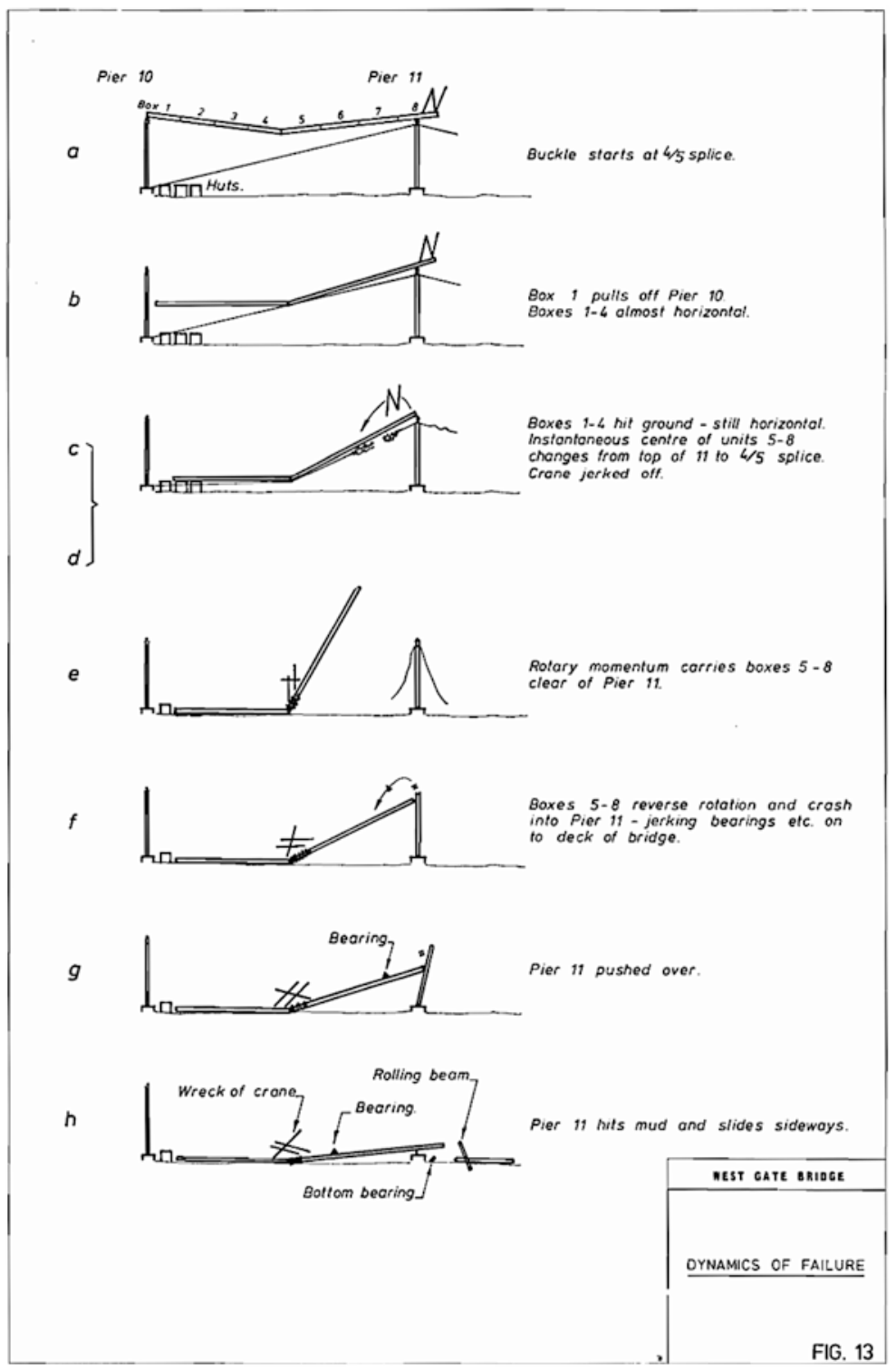

Illustration 2.2 "Dynamics of Failure". (Source: Royal Commission, Appendix, p. 134) 


\subsection{Case Analysis}

\subsubsection{Turning Points and Critical Junctures}

According to the Royal Commission, neither the unusual and sophisticated method of assembling and lifting the box girders nor the fragmented and conflict-ridden structure of management and control in the triangle of LYCA, the joint consultants Maunsell and FF \& P and the main contractors WSC and JHC had made the disaster of 15 October 1970 unavoidable. Still, the Commission stated by way of conclusion, mindful officials, consultants and senior engineers would and should have been able to handle those complex technical and organizational conditions if only they would have been mindful and determined enough to do so. ${ }^{98}$ While the assessment in the present study differs from the Commission's judgment to the extent that the latter implied the possibility of professional skill that, if existent, would probably have prevented the emergence of a risk-prone technical and organizational structure in the first place, there is good sense in acknowledging the proverbial forks in the road where alternative pathways presented themselves but were not taken. There were turning points at which the resulting path dependency was relatively weak and critical junctures whose determining force in shaping the remaining pathway was relatively strong.

The first turning point of major importance was, in 1966, the creation of a quasi-non-governmental organization (QUANGO) as supervising authority for the public works connected with the construction of the West Gate Bridge. This at least reduced the possibility to shield off interference of private interests, business interest in particular, since the authority itself, the Lower Yarra Crossing Authority (LYCA), was not only initiated and literally created by the private business community but also governed by private enterprises whose interests were vested in the construction of what became the West Gate Bridge. By the same token, LYCA was not financed through the state budget but through private loans whose repayment was guaranteed by the state of Victoria.

LYCA's solid embeddedness in the local business community did play a role when, in early 1970, the Authority had to decide whether or not to continue business with the Dutch contractor WSC. This was a critical juncture indeed. And LYCA's decision to discontinue the cooperation

${ }^{98}$ Royal Commission, 88. 
with WSC as far as the main part of the steelworks of the bridge was concerned was, according the Royal Commission, at least indirectly influenced by the institutional choice of how to create and to govern LYCA itself. After all, LYCA was working with borrowed money which left it with no choice but to exert massive pressure on WSC when the Dutch contractor turned out to be way behind schedule with the completion of the assigned works. Moreover, when a local alternative presented itself in the form of John Holland Constructions Proprietary Ltd. (JHC) it seemed to be one more time a natural choice, especially since JHC was already present on the construction site as the contractor for all concrete related works. Despite all the plausibility of this choice, the Royal Commission maintained that LYCA should have invested more effort in keeping the initial contract with WSC (Contract S) but it also pointed to the incentives not to do so. What mattered in the perception of LYCA was not only the undeniable time pressure but also the alleged smooth relationship of JHC with labor and the plausible assumption that JHC's well-known lack of experience and professional competence concerning sophisticated steelworks could be offset by close cooperation with FF \& P as main consultant for structural engineering. So the decision to discontinue Contract $S$ with WSC was plausible but nonetheless irreversible and fateful in its consequences. A productive cooperation between JHC and FF \& P never materialized. Necessary measures of risk-assessment and related calculations did not take place. Division of labor between JHC and FF \& P/Maunsell as well as the remaining tasks of WSC as quasi-consultant in support of JHC remained more than blurry.

A turning point in the sense that the course of events was not decisively shaped but accentuated was the collapse of the Milford Haven Bridge in Wales on 2 June 1970. Although occurring in faraway Great Britain, the disaster impacted significantly on the situation in Melbourne because FF \& $\mathrm{P}$ had been the chief designer of the Milford Haven Bridge. And the design itself was quite similar to the one of the West Gate Bridge now under construction. This prompted LYCA's general manager C. V. Wilson to express explicit safety concerns as far as the West Gate Bridge was concerned. A sharp confrontation between Wilson and FF \& P's Resident Engineer, Jack Hindshaw, followed. As a tragic consequence, Hindshaw, according to the findings of the Royal Commission, developed the attitude to conceal existing engineering problems occurring in the course of the construction of the bridge, the erection of the steelworks in 
particular. ${ }^{99}$ The most consequential of these efforts was Hindshaw's decision to straighten the buckle occurring on span 10-11 of the bridge, an instruction executed the morning of 15 October 1970. This he did, according to the judgment of the Royal Commission, out of embarrassment, being "concerned that Wilson should not see the buckle". ${ }^{100}$ The decision was the immediate trigger of the collapse of span 10-11 the same morning at 11:50AM.

While the consequences of the collapse of the Milford Haven Bridge of 2 June 1970 were quite indirect though counterintuitive in nature, two episodes preceding the critical works on the west side of the West Gate Bridge strengthened a fatal path dependency. One was, quite ironically, the successful dealing with a buckle on the plate edge of the north boxes of span 14-15 located on the east bank of the river Yarra, the other one was a meeting held on 16 September 1970 between representatives of WSC, Maunsell and FF \& P at which the joint consultants gave unsubstantiated assurances on the general safety margins of the erected steelwork of the bridge.

What had happened during the erection phase of span 14-15 on the east side of the bridge established was, according to the Royal Commission, a dangerously misleading pattern of problem solving should bending stress affecting the box girders and the covering plates and related buckles occur. In the case of span 14-15 a remaining buckle had been straightened through the temporary removal of bolts that had connected three individual boxes in order to reach flexibility of the box in the middle which had indeed the desired effect of flattening out the buckle. The tragedy was that on 15 October 1970 under apparently similar conditions-i.e., when a buckle occurred on span 10-11 on the west side of the bridge-the same technique was applied. This was done, however, hastily and without diligent and accurate assessment of the actual conditions at span 10-11, especially as far as bending stress was concerned. When, according to the pattern applied at span 14-15, two boxes within span 10-11 were unbolted on 15 October 1970 the procedure triggered the collapse of the entire span 50 minutes later. Certainly, the pattern established at the east side of the bridge months before was not a strictly determining factor but the Royal Commission was convinced that the fatal decision to unbolt the relevant boxes of span 10-11 on the west side of the bridge was made in

\footnotetext{
${ }^{99}$ Royal Commission, 28.

${ }^{100}$ Royal Commission, 25.
} 
full confidence that the buckle there could be handled the same way the previous buckle at the east side had been dealt with. ${ }^{101}$

The ultimate critical juncture that almost inevitably opened the gate to disaster was therefore an on-site meeting held 16 September 1970 at which JHC's chairman and managing director, C. V. Holland, was present and explicitly requested assurances on the overall safety margins of the bridge. This would have been the opportunity to give a sober account of all relevant safety assessments. After all, it was the chief executive of JHC himself who asked the most relevant of all questions, addressed to engineers of the joint consultants, FF \& $\mathrm{P}$ in particular, whose expertise and responsibilities specifically pertained to all relevant calculations. The consultants gave the safety assurances Holland had asked for. Almost parallel to this on-site meeting, another $\mathrm{JHC}$ representative, project manager T.R. Nixon, wrote to WSC's senior representative G. Hardenberg who despite WSC's dismissal from the initial contract concerning the steelworks of the bridge still served as an advisor on erection method and technique. Nixon was seeking Hardenberg's opinion on "the adequacy of the structure in its present condition to properly withstand erection stresses". ${ }^{102} \mathrm{He}$ raised the same question to Maunsell and FF \& P. Hardenberg replied to Nixon on 16 September 1970 that "the structure is quite adequate to allow erection of box $12 " .{ }^{103}$ Although this answer was more specific than the general assessment Nixon had asked for it came in a similar vein as the assurance of Maunsell and FF \& $\mathrm{P}$ given to Nixon's boss, Hardenberg, at the on-site meeting the very same day.

The Royal Commission concluded that "the effect of Hardenberg's letter, combined with the assurance of the joint consultants, was to give JHC a false sense of security." After all, neither Hardenberg, representing WSC, nor Maunsell or FF \& P had based their assurances on recent calculations. The Royal Commission clearly stated, "had Hardenberg refused the assurances sought from him JHC might well have declined to proceed further with the erection [of the steelwork of the bridge]" since he "had no justification for the reassuring opinion he expressed". ${ }^{104}$ The path dependency emerging from here was that the absence of calculations to be provided either by WSC or FF \& P or both was not compensated by

\footnotetext{
${ }^{101}$ Royal Commission, 19.

${ }^{102}$ Royal Commission, 99.

${ }^{103}$ Ibid.

${ }^{104}$ Ibid.
} 
JHC's own staff. When JHC engineers suggested to use kentledge in order to reduce the camber between the north half and the south half of the bridge near span 10-11 to an acceptable level and thus committed in fact "the gravest of errors" 105 they had "no calculations available giving them any knowledge of the stresses likely to be created". ${ }^{106}$ It was the kentledge, however, that caused the buckle to appear on span 10-11 whose removal was hastily initiated the morning of 15 October 1970.

The meeting of 16 September 1970 turned out to be the classic missed opportunity to do what was imperative namely "to put any question of safety beyond reasonable doubt" ${ }^{107}$ Instead, appropriate steps to do so fell prey to an organizational and contractual arrangement that systematically generated the type of organized irresponsibility aptly characterized by the Royal Commission (Fig. 2.1):

A contractor more familiar with the erection of large steel bridges might have recognized the danger signs more readily. The consultant engineers on site do not appear to have taken the matter sufficiently seriously, while the consultants in London did not consider the matter at all, because they knew nothing of either kentledge or buckles until after the bridge had fallen. ${ }^{108}$

\subsubsection{Contributing Factors, Necessary and Sufficient Conditions}

In its report, the Royal Commission stated that none of the organizational and contractual arrangements, however insufficient and unsatisfying in detail, sufficiently explains the occurrence of the serious engineering problems on the construction site of the West Gate Bridge and the ultimately disastrous attempts to solve them. This remains an ambivalent statement since, on the one hand, it underlines the role of guidance and management especially under circumstances that are difficult and challenging in terms of coordination and risk-management while, on the other hand, the Commission's judgment missed one important point: What should justify the assumption that the very key-actors responsible for the awkward and risk-increasing organizational and contractual arrangement established for the construction of the West Gate Bridge could have been able to handle

\footnotetext{
${ }^{105}$ Royal Commission, 102.

${ }^{106}$ Ibid.

${ }^{107}$ Royal Commission, 66.

${ }^{108}$ Ibid.
} 


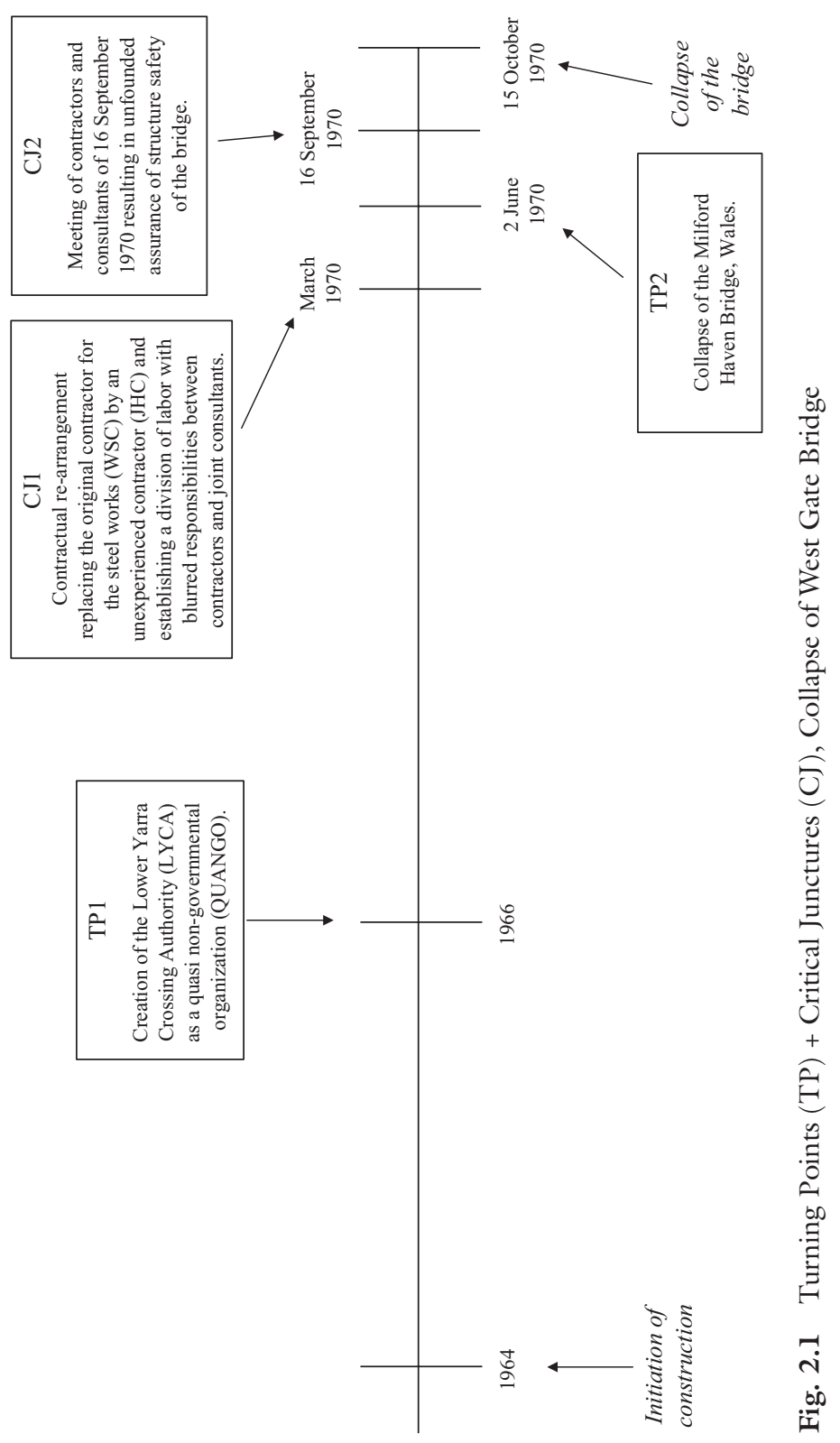


these conditions with professional skill and the necessary sense of responsibility? To that extent the Commission's assessment is rather a normative plea with the benefit of hindsight than a neutral analysis of the interplay of structural conditions and human agency that paved the way to the disaster of 15 October 1970.

While it is true that the collapse of the West Gate Bridge was a manmade disaster in an almost classic sense, errors of design-technical and organizational in nature-and errors of situational judgment have to be distinguished. Some of the design errors can be characterized as necessary conditions of the disastrous outcome in the sense that without them the rest of the causal chain would have been unthinkable or at least highly unlikely to occur. Some of the judgment errors, however, can be characterized, actually quite in accordance with the conclusions of the Royal Commission, as sufficient conditions in the sense that, under the given circumstances, they made the disaster inevitable.

There were, however, antecedent conditions to which the Royal Commission's skeptical judgment can be applied as risk factors in their own right. This affects the nature of LYCA, the fragmented governance of the entire planning and construction process and the unique and unusually challenging method of erection of the steelworks chosen by WSC. LYCA as sole representative of the public interest was no public authority in the proper sense. Instead, it was a private organization both in legal terms and as far as its stakeholders and, above all, as far as its financial commitments were concerned. LYCA basically represented the business community and it was working with borrowed money. The only constitutive element of public interest was the fact that the state of Victoria guaranteed the status of LYCA as a first class debtor. This, however, did not make LYCA an independent authority robust enough to shield off collisions of interest. For instance, it was the fact that financial obligations were piling up already in 1969 due to the substantial delay of the works assigned to WSC which soon would pave the way to an entirely new contractual arrangement in the framework of which WSC was replaced by $\mathrm{JHC}$ as a contractor with no experience in erecting steelwork-based box girder bridges. Yet, the stakeholder background and the nature of LYCA as a private organization assuming tasks of a public authority cannot be classified as a necessary condition in the sense that a different type of institutional arrangement, typically a public agency in the proper sense, would have made the ensuing components of the causal chain unthinkable or highly unlikely. LYCA had all the necessary means and competences to 
supervise and control the planning and construction of the West Gate Bridge in full accordance with the necessary safety requirements.

The same holds true even for the fragmented governance of the entire planning and construction process concerning the West Gate Bridge. To some extent, it was the epitome of unnecessary organizational complexity inviting the relevant actors to silo-thinking and blame-avoidance in the triangle of LYCA as a quasi-nongovernmental organization, the "joint consultants" Maunsell and Partners and London-based FF \& P plus the actual contractors JHC and WSC. But, again, this kind of structure was, basically, not entirely unusual in the realm of public works and, specifically, in the field of bridge construction. So it was, in principle, manageable as well.

What made both of these anteceded factors critical in terms of riskmanagement was, however, a crucial technical aspect of the ultimate erection of the bridge that, according all likelihood, could not have been anticipated in all clarity by the joint consultants, let alone LYCA: WSC, the contractor in charge of the steelworks of the bridge, decided to construct and to erect the two parallels halves of the overall span of the box girder bridge separately. Instead of cantilevering in a piecemeal way the integral components of the box girders up in the air as usual, WSC's method of choice was to assemble the steel boxes on the ground, to bolt them together to girder segments and to lift those up to top-of-pier level at a height of 170 feet. This method was risk-prone in at least two respects. Accuracy and diligence when assembling the boxes on the ground were of the essence. Moreover, since the two half spans, the north part and the south part, were prefabricated and lifted separately camber between the two halves was likely to occur.

Yet, these intricacies of structural engineering were certainly not beyond managerial control either. It was only in combination with the likewise complex governance of the entire planning and construction process of the West Gate Bridge that the technical particularities turned out to be the decisive risk factor as far as engineering as such was concerned. If the keyactors in the triangle of LYCA, joint consultants and contractors would have been aware of the combined technical and managerial risk zones and mindful enough to address them appropriately the risks themselves could have been kept under control. The problem was precisely the absence of that kind of awareness and mindfulness among the key-figures running the complex machinery of planning, controlling and construction. Which 
leads us to the inner circle of necessary and sufficient conditions of the ultimate disaster to occur.

What one can define as the one necessary condition without which the rest of causal chain resulting in disaster according to all likelihood would not have evolved is the contractual rearrangement of tasks and responsibilities between the contractors WSC and JHC and the joint consultants Maunsell and FF \& P that took place in March 1970. It was initiated by LYCA in response to the serious delays of the steelwork portion of the construction assigned to WSC. WSC engineers and managers were exhausted by protracted conflicts with organized labor and, consequently, more than ready to withdraw from their initial contractual obligations as soon as LYCA indicated its own readiness to relinquish WSC from substantial penalty fees accumulated through the considerable delay of the completion of the steelworks. As a result of the rearrangement, JHC stepped in as substitute contractor replacing WSC and thus assuming the task of completing the steelworks.

The fact that JHC lacked the special expertise necessary for the work involved was, as the Royal Commission wrote, "manifestly plain" to LYCA. ${ }^{109}$ It was therefore agreed upon that WSC would continue to serve as an advisor in all questions of the practical erection of the steelwork itself while the general oversight and the specific tasks connected to issues of structural engineering were assigned to the joint consultants Maunsell and FF \& P. Among them, in turn, the division of labor was such that Maunsell was in charge of administrative and managerial aspects while FF \& P was in charge of overseeing engineering itself including the relevant calculations. FF \& P thus had to coordinate the activity of its engineers on the construction site in Melbourne and the supporting advice and control of FF \& P headquarters in London. JHC was now the sole contractor for the entire construction of the bridge and thus in a strong position as LYCA's last hope as far as the successful completion of the entire bridge works was concerned. In protracted negotiations before the final signing of a new contract (Contract E) in July 1970, JHC insisted on limiting its responsibilities strictly to mere construction thus discarding any responsibility for issues of structural engineering and related calculations. Yet, JHC engineers, after assuming the new task of completing the steelworks without substantial experience in that field, became, according to the findings of the Royal Commission, "over-confident" which, according to the

${ }^{109}$ Royal Commission, 101. 
Commission, implied a "course of conduct [that] resulted in the breakdown of the arrangement originally envisaged by the Authority [LYCA] and the joint consultants". ${ }^{110}$

However, the "arrangement originally envisaged" was a syndrome of organized irresponsibility anyway. Not only made it an inexperienced contractor in charge of an unique and particularly complex method of erection of the steelwork but at the same time exempted the very contractor by the very same reasons-lack of experience-from the "sophisticated calculations and highly technical decisions necessary to ensure the safe and satisfactory completion of the contract". ${ }^{111}$ This was, according to all evidence, a high risk arrangement and therefore the opposite of what was required under the already difficult conditions of an unusually complex method of erection of the steelwork part of the bridge. Which leaves little doubt that without the replacement of WSC by JHC in March 1970 and the formal agreement laid down in Contract E signed on 10 July 1970 the ensuing wrongful decisions and omissions would not have evolved.

Still, even the arrangement of Contract E, however risk-increasing, did not trigger the disaster quasi-automatically. The Royal Commission was right in emphasizing that careful handling of what meanwhile was a highrisk governance structure still could have prevented the errors and omissions that resulted in the catastrophe. The sufficient condition for the disaster to occur was indeed the failure of a handful of chief engineers of the contractors and the joint consultants who should have acted as professional "linking pins" in what had emerged as a fragmented yet manageable network of firms and individuals. Their mutual relationship was characterized by rivalry instead of trustful cooperation, withheld information instead of transparency and pugnacious rather than conflict-mitigating attitudes. This culminated in a meeting of WSC, Maunsell and FF \& P engineers on 16 September 1970 as a result of which unsubstantiated assurances confirming the overall stability and stress resistance of the steelwork of the bridge were given to JHC. No proper and specific calculations had been made on which such assurances could have been founded. Neither were any such assessments performed prior to the fatal decision to temporarily remove a major number of bolts at the slice of two boxes of

${ }^{110}$ Ibid.

${ }^{111}$ Ibid. 
span 10-11 in an attempt to straighten a buckle- the immediate trigger of the disaster of 15 October 1970 (Table 2.1).

\subsubsection{Causal Mechanisms}

The distinction of necessary and sufficient conditions just like the distinction of turning points and critical junctures is case-specific and, accordingly, of limited value for generalization. Certainly, scholarly experts and, especially, seasoned practitioners will recognize typical patterns of both ill-conceived organizational and contractual arrangements and lack of professional skill. Yet, there is an inevitable epistemological gap between the uniqueness of causality in a given case of disaster and the quest for generalization in terms of predictability for the sake of prevention. That gap cannot be entirely closed but substantially reduced in a differentiated perspective on causal mechanisms.

The circumstances under which key-actors in Melbourne started to build what was deemed a necessary organizational and contractual arrangements for satisfying the quest for a bridge crossing the Lower Yarra River were rather conventional in nature. However, the question arises what the driving mechanisms were behind the choice of a particularly risk-prone arrangement and to what extent those mechanisms can be generalized. A subsequent question concerns the actual risk-taking and risk-increasing behavior of the key-actors involved. What were the characteristic behavioral patterns and to what extent did they contribute to the disastrous outcome of the causal process under scrutiny? Finally, what can be generalized when it comes to the question why points of intervention were not recognized in a timely manner and what lowered the threshold that

Table 2.1 Contributing Factors (CF), Necessary Condition (NC) and Sufficient Condition (SC), Collapse of West Gate Bridge

CF1 Nature of the Lower Yarra Crossing Authority (LYCA) as a Quasi NonGovernmental Organization (QUANGO).

CF2 Unusual and particularly sophisticated method of bridge erection.

NC Contractual re-arrangement of tasks and responsibilities between contractors and joint consultants, March 1970 (made official 10 July 1970), and transfer of main part of works to contractor with no experience with complex steelworks.

SC Meeting of contractors and consultants of 16 September 1970 resulting in unfounded assurance of structure safety of the bridge. 
separated risk-increasing behavior of key-actors from the actual occurrence of the disaster?

Following what Hedström and Ylikoski suggested in terms of discernable situational, action-formation and transformational mechanisms ${ }^{112}$ as outlined in the introduction to this book, it is through the lenses of ontologically specific theories that we recognize relevant mechanisms and it is with the help of those theories that related diagnoses can be generalized for the sake of predictability and prevention.

As far as situational mechanisms are concerned, an initial institutional choice resulted in the creation of The Lower Yarra Crossing Authority (LYCA) as a private institution in charge of securing a vital public interest-the safety of a roadway bridge. LYCA was a quasi-non-governmental organization or QUANGO, ${ }^{113}$ a type of organization that, almost by definition, weakens enforcement capability. ${ }^{114}$ The flipside of blame-avoidance was the actual diffusion of responsibility. Fragmented jurisdiction for what was a technically complex and challenging project anyway implied information asymmetries at the expense of the control capacity of both LYCA and the joint consultants Maunsell and FF \& P. These mechanisms were inherent to the initial institutional choices and contractual arrangements regardless of any individual behavioral attitude of the key-actors involved.

However, those key-actors did not withstand, let alone neutralize, the incentives of the situational mechanisms. Rather, they brought to bear the undesirable effects in the form of particular action-formation mechanisms. A typical pattern here was silo-thinking and related selective perception of what actually required an integral plan and comprehensive planning. ${ }^{115}$ This applied to both LYCA, the contractors WSC and JHC and to the joint consultants Maunsell and FF \& P. Basically, all of these institutional actors and their individual representatives followed their own agenda

${ }^{112}$ Peter Hedström and Petri Ylikoski: Causal mechanisms in the Social Sciences. Annual Review of Sociology 36 (2010): 49-67.

${ }^{113}$ Carsten Greve, Matthew Flinders, and Sandra Van Thiel: Quangos-What's in a Name? Defining Quangos from a Comparative Perspective. Governance 12 (1999): 129-146; Flinders, Matthew V., and Martin J. Smith: Quangos, Accountability and Reform. The Politics of Quasi-Government. London: Palgrave Macmillan 1999.

${ }^{114}$ For a classic description of softening institutional integrity through delegating authority to an independent public agency cf. Philip Selznick: TVA and the Grassroots. A Study in the Sociology of Formal Organization. Berkeley and Los Angeles: University of California Press 1949.

${ }^{115}$ DeWitt C. Dearborn and Herbert A. Simon: Selective Perception: A Note on the Department Identifications of Executives. Sociometry 21 (1958): 140-144. 
according to what the institutional and contractual arrangement suggested in the first place. From this resulted a culture of blame avoidance ${ }^{116} \mathrm{com}$ bined with a mild type of regulatory capture. ${ }^{117}$ Rather than controlling the contractors and the joint consultants, LYCA came under pressure from JHC when the Authority, in its own perception, had no choice but to accept JHC as supplement contractor for the steelworks of the bridge replacing WSC. Banking on its own indispensability, JHC achieved substantial concessions from LYCA as far as the limitation of responsibilities was concerned and, consequently, related liability risks. These concessions were virtually made at the expense of the public interest in safe and sound construction and related mechanisms of control and accountability.

Still, just as the Royal Commission concluded in its report, the riskgenerating consequences of organizational and contractual choices and the risk-increasing impact of resulting behavioral attitudes of key-actors could have been neutralized by mindful and determined management. Accordingly, what can be classified as ultimate trigger factor or transformational mechanism was the absence of appropriate leadership, a sense of responsibility in particular. ${ }^{118}$ Both the notion and the reality of responsibility had evaporated. This pertained to awareness in general as well as to conflict management and the managerial and social skills to reintegrate a highly fragmented governance structure. Basically, none of these managerial virtues and attitudes came to bear so that, in the essence, the failure of the West Gate Bridge was, according to the Royal Commission, the consequence of mismanagement and failed leadership (Fig. 2.2).

${ }^{116}$ Christopher Hood: The Blame Game: Spin, Bureaucracy and Self-Preservation in Governments. Princeton and Oxford: Princeton University Press 2011.

${ }^{117}$ Cf. again Selznick, TVA and the Grassroots. For more recent analyses cf. Ernesto Dal Bó: Regulatory Capture: A Review. Oxford Review of Economic Policy 22 (2006): 203-225; Daniel Carpenter and David A. Moss, eds.: Preventing Regulatory Capture. Special Interest Influence and How to Limit It. Cambridge: Cambridge University Press 2014.

${ }^{118}$ Herman Finer: Administrative Responsibility in Democratic Government. Public Administration Review 1 (1940): 335-350; Mark Bovens: The quest for responsibility: Accountability and citizenship in complex organisations. Cambridge: Cambridge University Press 1998; Paul 't Hart and Lars Tummers: Understanding Public Leadership. 2nd ed., London: Red Globe Press 2019. 


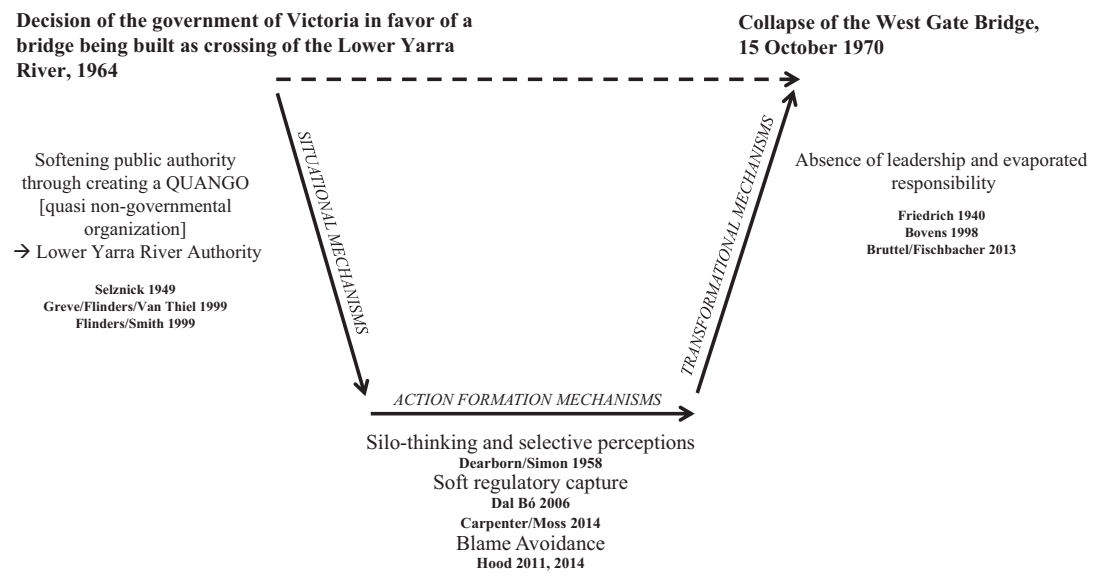

Fig. 2.2 Causal Mechanisms, Collapse of West Gate Bridge

Open Access This chapter is licensed under the terms of the Creative Commons Attribution 4.0 International License (http://creativecommons.org/licenses/ by $/ 4.0 /$ ), which permits use, sharing, adaptation, distribution and reproduction in any medium or format, as long as you give appropriate credit to the original author(s) and the source, provide a link to the Creative Commons licence and indicate if changes were made.

The images or other third party material in this chapter are included in the chapter's Creative Commons licence, unless indicated otherwise in a credit line to the material. If material is not included in the chapter's Creative Commons licence and your intended use is not permitted by statutory regulation or exceeds the permitted use, you will need to obtain permission directly from the copyright holder.

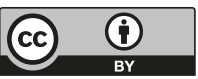

